\title{
Clinical Outcomes of Total Laparoscopic Hysterectomy (TLH): Seven Years' Experience in a Public Hospital
}

\author{
JOBAIDA SULTANA ${ }^{1}$, MANIR HOSSAIN KHAN ${ }^{2}$, FATEMAASHRAF ${ }^{3}$, MAHMUDA SULTANA $^{4}$, \\ MARIHA ALAM CHOWDHURY 5
}

\begin{abstract}
:
Objective: The aim of the study was to explore the surgical outcomes of total laparoscopic hysterectomy.

Materials and methods: This was a prospective analysis of total Laparoscopic Hysterectomy (TLH) done between January, 2012 to December, 2018 in Shaheed Suhrawardy Medical College and Hospital. Demographic data, clinical criteria, intra operative and postoperative outcome data were recorded. Data were collected in a predesigned Data collection sheet. Follow up records done during discharge from the hospital, one week and four weeks postoperatively.

Results: Total 298, laparoscopic hysterectomy were performed during the period. Among them $96 \%(n=286)$ for benign and $4 \%(n=12)$ for malignant condition were included in the study population. Mean age of the patients was $45.4 \pm 5.6$ years, mean parity was $1.9 \pm 0.64$ and the mean body mass index was $27.48 \pm 0.57$. The most common benign disease was leiomyoma, $51.7 \%$. Among the study cases $21.8 \%(n=65)$ had history of at least one previous abdomino-pelvic surgery. Maximum size of uterus removed was 28 weeks and maximum patients, $48 \%(n=143)$ had uterine size of $10-14$ weeks. The operating time was variable between 50 min to $180 \mathrm{~min}$ and in the course of time, the mean operating time dropped from $130 \mathrm{~min}$ to $60 \mathrm{~min}$. The mean length of hospital stay was 2 days and the return to normal activities was within 2 weeks.

Major complications observed among $3.7 \%$ of cases among them 2(0.67\%) bladder injury, $2(0.67 \%)$ vesico-vaginal fistula (VVF), 3(1.0\%) ureterovaginal fistula (UVF) and 4(1.3\%) peroperative hemorrhage requiring blood transfusion. Among the 7 cases of urological complications, one patient with VVF and one patient with UVF needed relaparotomy. Ultimately all cases were managed without any residual problem. Conversion to laparotomy was $0.3 \%$ $(n=1)$ of case.
\end{abstract}

Conclusion: TLH offers the benefit of minimally invasive surgery to the patient and is a safe and acceptable alternative to standard hysterectomy for various gynaecological indications.

Keywords: Total laparoscopic hysterectomy, Per operative complications, Follow up.

\section{Introduction:}

Hysterectomy is the commonest major gynecological operation and a vast majority of the procedures are performed for benign conditions ${ }^{1,2}$. There are three approaches to hysterectomy; abdominal, vaginal and laparoscopic hysterectomy. The indications for laparoscopic hysterectomy are similar to the generally accepted indications for abdominal hysterectomy.

1. Dr. Jobaida Sultana, Associate Professor, Department of Obstetrics and Gynaecology, Shaheed Suhrawardy Medical College and Hospital, Dhaka

2. Dr. Md. Manir Hossain Khan, Associate Professor, Department of Surgery, BSMMU, Dhaka

3. Professor Fatema Ashraf, Professor and Head, Department of Obstetrics and Gynaecology. Shaheed Suhrawardy Medical College and Hospital, Dhaka

4. Dr. Mahmuda Sultana, Junior Consultant, Department of Obstetrics and Gynaecology, Shaheed Tajuddin Ahmed Medical College and Hospital, Gazipur

5. Dr. Mariha Alam Chowdhury, Consultant, Department of Obstetrics and Gynaecology, Praava Health, Dhaka

Address of Correspondence: Dr. Jobaida sultana, Associate Professor, Dept. of Obstetrics and Gynaecology, Shaheed Suhrawardy Medical College \& Hospital, Dhaka, Bangladesh. Mobile: 01819250728, E-mail: jobaidasultana @ gmail.com 
Nowadays, laparoscopy is being increasingly adopted in addition to the traditional open access. Data from the United States, in $2000,74.5 \%$ of hysterectomies were abdominal, $22.2 \%$ vaginal and $3.3 \%$ laparoscopic; in contrast, in 2010 , only $36.6 \%$ of hystecrectomies were abdominal and $17.2 \%$ were vaginal while $43.5 \%$ of cases were laparoscopic ${ }^{3}$. There are many advantages of laparoscopic approach like avoidance of painful abdominal incision, shorter hospital stay, faster recovery and early return to activities. Reich in 1989-first performed laparoscopic hysterectomy ${ }^{4}$. In Bangladesh, first diagnostic laparoscopy was started in 1978 by Prof T. A. Chowdhury and in 1996, Prof. Laila Arzumand Banu \& Dr. Sarder A. Nayeem performed the first $\mathrm{LAVH}^{5}$ in Bangladesh. Since the introduction of laparoscopic hysterectomy, several modifications have been described. These are laparoscopy assisted vaginal hysterectomy (LAVH), laparoscopy assisted supracervical hysterectomy ( $\mathrm{LSCH}$ ) and total laparoscopic hysterectomy (TLH) ${ }^{6,7}$. In TLH, the laparoscopic dissection continues until the uterus lies free of all attachments in the peritoneal cavity, the uterus is removed through the vagina or through one of the ports with the help of morcellation if necessary. After removal, vagina is closed by intracorporeal sutures laparoscopically ${ }^{8}$. Laparoscopic hysterectomy has a longer learning curve during which the risk of complications is relatively higher than abdominal hysterectomy ${ }^{9}$. Later gynecologic surgeons have made many efforts to improve the technique thereby shortening the learning curve and improve outcomes, reducing iatrogenic urinary-tract injuries, intra operative blood loss, hospitalization time, and recovery time ${ }^{10}$. Now with the improvement of surgical skills, it has been considered as a day care surgery ${ }^{11}$. The aim of this study was to explore the surgical outcomes of total laparoscopic hysterectomy.

\section{Materials and methods}

This was a descriptive type of prospective study, done from January, 2012 to December, 2018. Total 298 cases of total laparoscopic hysterectomy were performed in Shaheed Suhrawardy Medical College \& Hospital. All cases suitable for laparoscopic hysterectomy were included. Patients with the contraindications for laparoscopic hysterectomy and those refused to have laparoscopic surgery were excluded from the study. Demographic data, clinical criteria of all patients together with intraoperative and postoperative outcome data were recorded during preoperative, post operative and follow up period.

\section{Surgical Technique}

After counseling the patient, informed consent was obtained. Bowel preparation was given, the day before surgery in outdoor basis and kept nil per oral for a minimum of 6 hours. Patients were admitted on the day of operation. All patients received preoperative intravenous prophylactic antibiotics.

The patient under general anesthesia in the modified semi-lithotomy position, and deep Trendelenburg position with a bolster under the buttocks the operatoin was started. This position offers elevation of the pelvis and results in drop of the intestines cephalad. Bladder catheterization was done. The surgeon always stand by the left side of the patient.

Four laparoscopic ports were used according to size of the uterus. Usually the primary trocar $(10 \mathrm{~mm})$ was placed supraumbilically mostly by blunt techniques and sometimes by open method. After insufflation with carbon dioxide, a 10-mm telescope was introduced, and entry site was inspected for any injury. Then three secondary $5 \mathrm{~mm}$ ports were introduced, two on left and one on right side or suprapubic region. Palmer's point entry was done in patients with suspected adhesions with multiple previous surgeries.

Harmony scalpel, bipolar and monopolar diathermy were used as energy source. The pelvis and abdomen were inspected for every- adhesions, endometriotic spots, size of uterus, tubal, and ovarian pathology. A 5-mm myoma screw was inserted into the uterine fundus and uterus retracted cephalad, and to the left. Since 2014, a vaginal manipulator was used for vaginal manipulation. The right round ligament, ovarian ligament and the fallopian tube were coagulated and cut by Harmonic scal pel. The anterior leaf of broad ligament was opened and an anterior " $U$ " incision taken through the uterovesical fold. The urinary bladder was dissected out over the cervix by sharp and blunt dissection. Right sided uterine artery was skeletonized and first coagulated by bipolar then cut by harmonic. With continuous traction on uterus the posterior peritoneum and parametrial tissue on the lateral aspect of cervix was coagulated and cut by harmonic. The dissection was always kept above the level of the uterosacral ligament. Then same procedure done on the left side. At this moment a vaginal colpo-bulger was used to clearly delineate the cervico-vaginal junction. A circular incision was given thereby cutting the Mckenrodts and uterosacral ligament and opening of vault. For patients with removal of ovaries, the infundibulopelvic ligament was cauterized by bipolar forcef and cut by Harmonic. In all cases bilateral salpingectomy was done. 
Specimen retrieved either by vaginal/laparoscopic morcellation depending on the size of the uterus. Vault was closed laparoscopically with vicryl no. 2-0 intra-corporeal suture. Adequate hemostasis was achieved.

\section{Data Analysis}

Statistical analysis was performed using SPSS for windows, version v 20.0.

\section{Result:}

Since 2012, a total 298, laparoscopic hysterectomy were performed. Among them $96 \%(n=286)$ for benign cases and $4 \%(n=12)$ for malignant cases. For benign cases, all were total laparoscopic hysterectomy.

Mean age of the patients was $45.4 \pm 5.6$ years. Regarding parity, $4.5 \%$ were nulliparous while the mean number of children were $1.9 \pm 0.64$ in multiparous group. The mean body mass index was $27.48 \pm 0.57$.

Indications for benign diseases were leiomyoma $51.7 \%$, adenomyosis $15.7 \%$, endometriosis $9.5 \%$, abnormal uterine bleeding (AUB) $7.4 \%$, ovarian cyst $5.6 \%$, pelvic inflammatory disease $4.5 \%$, postmenopausal bleeding $2.8 \%$ and endometrial hyperplasia $2.8 \%$ ( Table-I). Among 12 malignant cases, 5 patients were early stage endometrial cancer and underwent TLH with bilateral salpingooophorectomy (BSO) with bilateral pelvic lymph nodes dissection(PLND), 5 patients with borderline ovarian malignancies encountered TLH with BSO with omentectomy with bilateral PLND and 2 patients with early stage carcinoma cervix had radical hysterectomy with PLND (Table-II).

Regarding previous surgery $21.8 \%(n=65)$ had history of one previous abdomino-pelvic surgery. Of these, $58.4 \%(n=38)$ had previous one lower segment caesarean section (LSCS), $13.8 \%(n=9)$ had 2 LSCS, $4.6 \%(n=3)$ had three LSCS, $4.6 \%(n=3)$ had myomectomy, $7.7 \%(n=5)$ had ovarian cystectomy, $3.0 \%(n=2)$ had unilateral salpingooophorectomy and $7.7 \%(n=5)$ had appendicectomy (Fig-1). Maximum size of uterus operated was 28 weeks and maximum patients, $48.0 \%(n=143)$ had uterine size of 10-14 weeks (Fig-2). Morcellation of the uterus needed in $8.1 \%(n=24)$ of cases. Vault was closed laparoscopically in $95.0 \%(n=283)$ cases and vaginally in $5.0 \%(n=15)$ cases.
Table-I

Indications of Total Laparoscopic Hysterectomy (TLH) for benign cases $(n=286)$

\begin{tabular}{lcc}
\hline Indications & Number & $\%$ \\
\hline Leiomyoma & 148 & $(51.7)$ \\
Adenomyosis & 45 & $(15.7)$ \\
Endometriosis & 27 & $(9.5)$ \\
Abnormal Uterine Bleeding (AUB) & 21 & $(7.4)$ \\
Ovarian cyst & 16 & $(5.6)$ \\
Pelvic Inflammatory Disease & 13 & $(4.5)$ \\
Post-menopausal bleeding & 8 & $(2.8)$ \\
Endometrial hyperplasia & 8 & $(2.8)$ \\
\hline
\end{tabular}

Table-II

Indications of total Laparoscopic Hysterectomy (TLH) for malignant cases $(n=12)$

\begin{tabular}{lc}
\hline Indication & Number of patients \\
\hline Endometrial carcinoma & 5 \\
Borderline ovarian malignancy & 5 \\
Early stage carcinoma cervix & 2 \\
\hline
\end{tabular}

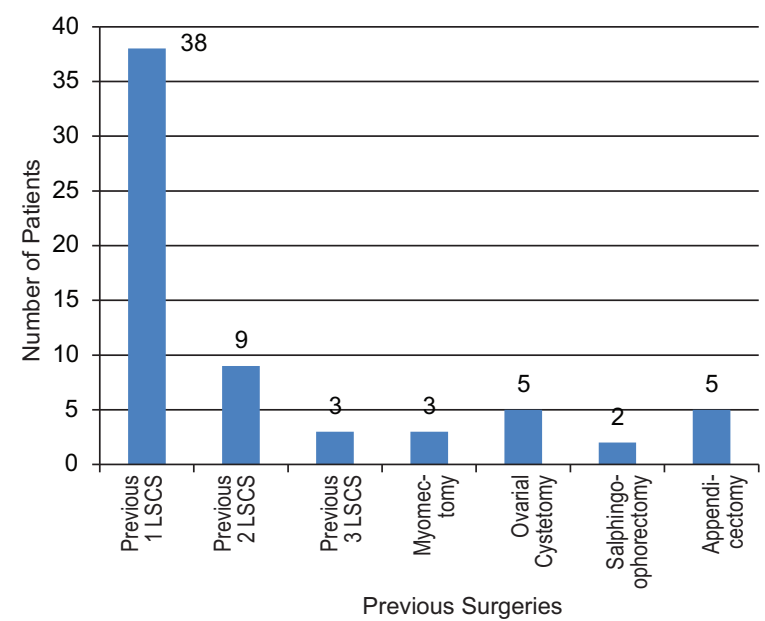

Fig.-1: Hysterectomy in patient with previous surgeries $(n=65)$

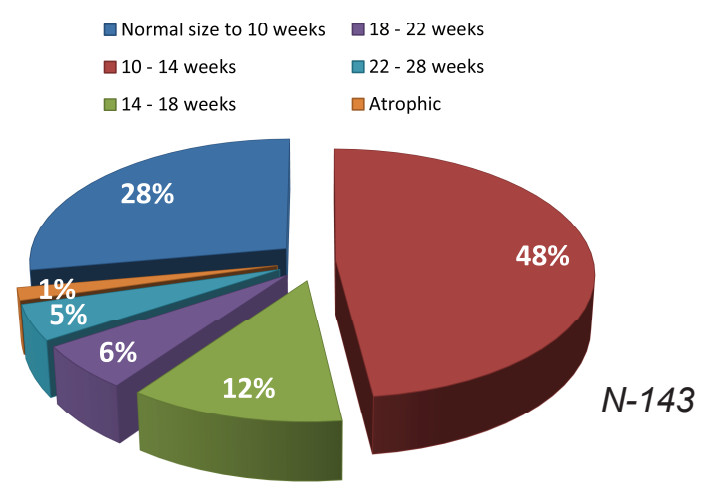

Fig.-2: Laparoscopic Hysterectomy and size of the uterus 
The operating time was between $60 \mathrm{~min}$ to $180 \mathrm{~min}$ for benign cases. In the course of time, the mean operating time dropped from $130 \mathrm{~min}$ to $60 \mathrm{mins}$ (Fig3). The mean operating time varied according to the size of the uterus from $60 \mathrm{~min}$ to $170 \mathrm{~min}$ (Fig-4). The mean operating time for malignant cases was $180 \mathrm{~min}$. The mean length of hospital stay was 2 days and return to normal activities within 2 weeks.

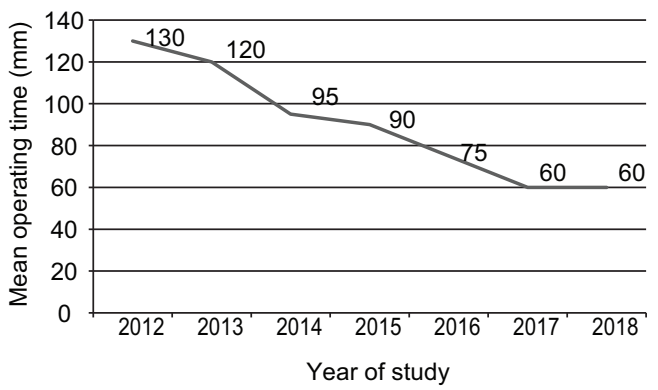

Fig.-3: Mean operating time (Size of uterus $<14$ weeks)

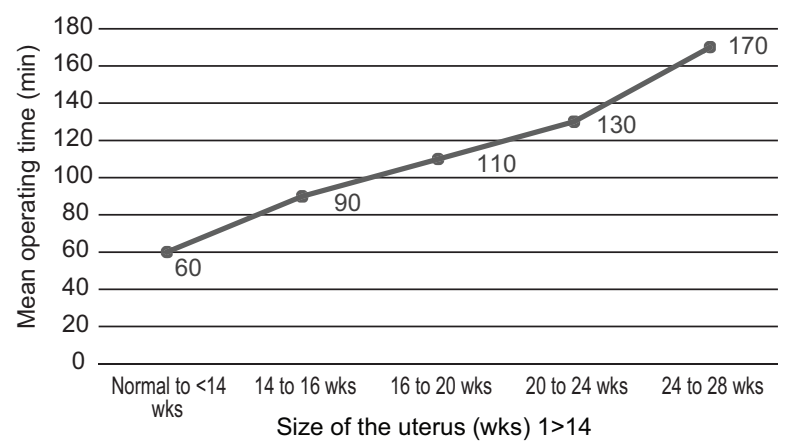

Fig.-4: Mean operating time according to the size of uterus for the year 2017 \& 2018

Concomitant procedures performed in $8.4 \%(n=25)$ of the patients, including cholecystectomy in $4.0 \%(n=12)$, appendicectomy in $1.7 \%(n=5)$, pelvic floor repair in $1.7 \%(n=5)$ and hernia repair in $1.0 \%(n=3)$ patients (Table-III).

Table- III

Concomitant procedure $(n=25) 8.4 \%$

\begin{tabular}{lc}
\hline Concomitant surgery & Number of patients \\
\hline Cholecystectomy & $12(4 \%)$ \\
Appendectomy & $5(1.7 \%)$ \\
Pelvic floor repair & $5(1.7 \%)$ \\
Repair of Hernia & $3(1 \%)$ \\
\hline
\end{tabular}

There was no complications in $93.0 \%(n=277)$ of the procedure, minor complications were seen in
$3.3 \%(n=10)$ of cases and major complications were observed in $3.7 \%(n=11)$ of cases (Fig-5). Conversion to laparotomy was only in $0.3 \%(n=1)$ case.

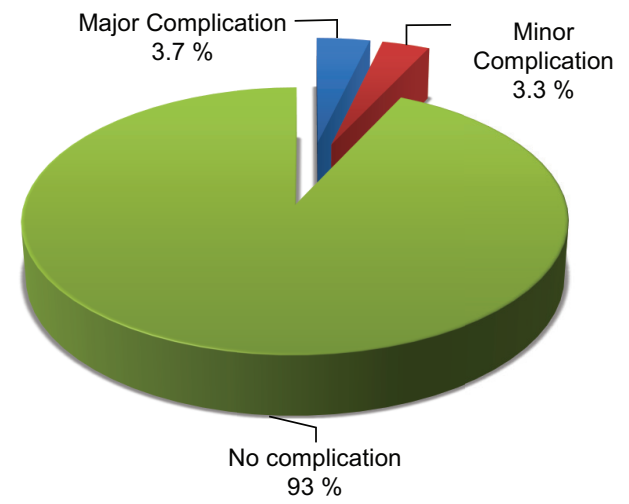

Fig - 5: Complication rate

Minor complications were slight $p / v$ bleeding, wound infection, UTI and vault granuloma (Table-IV) and managed conservatively.

Table-IV

Minor Complications, 3.3\% $(n=10)$

\begin{tabular}{lc}
\hline Type of complication & Number of patients \\
\hline Slight P/V bleeding & 4 \\
Wound infection & 3 \\
UTI & 2 \\
Vault granuloma & 1 \\
\hline
\end{tabular}

Patients having major complications, $0.67 \%(n=2)$ had bladder injury, $0.67 \%(n=2)$ had vesico-vaginal fistula(VVF), $1.0 \%(n=3)$ had ureterovaginal fistula (UVF) and $1.3 \%(n=4)$ had intra operative hemorrhage requiring blood transfusion. Among the 2 patients with bladder injury, one needed conversion to laparotomy due to extensive adhesion, then repair was done and in another patient repair was done laparoscopically. Among 2 cases of VVF, both were detected on $7^{\text {th }}$ postoperative day, one completely healed by continuous catheterization for 21 days and another repaired after 3 months. Among 3 patient who developed UVF, 2 developed on $2^{\text {nd }}$ postoperative day, they underwent cystoscopy and double j stents were kept in ureters for 4 weeks and then recovered completely. In 2 cases of UVF, later on detected and they had some developmental problems. Another patient who developed UVF on $7^{\text {th }} \mathrm{POD}$, did not come for follow up timely and she needed laparotomy after one month and re-implantation of ureter done in bladder. These patients were recovered without any residual problem. Table-V 
Table-V

Major Complications, 3.7\% ( $n=11)$

\begin{tabular}{l|l|l|l} 
Complications & $\mathbf{N}(\%)$ & Management & Course \\
\hline Bladder Injury & $2(0.67)$ & $\begin{array}{l}\text { Sutured intra-operatively } \\
-\quad \text { One needed conversion to laparotomy } \\
\text { due to extensive adhesion. } \\
-\quad \text { Another repaired laparoscopically } \\
-\quad \text { Catheterize for 21 days }\end{array}$ & $\begin{array}{l}\text { Uneventful } \\
\text { Long-term F/U - no problem }\end{array}$ \\
\hline VVF & $2(0.67)$ & $\begin{array}{l}\text { Both were detected on 7th POD. } \\
-\quad \text { One completely healed by } \\
\text { catheterization for 21 days. } \\
-\quad \text { Another repaired after 3 months. }\end{array}$ & $\begin{array}{l}\text { In long term F/U- no residual } \\
\text { symptoms }\end{array}$ \\
\hline UVF & $3(1)$ & $\begin{array}{l}\text { Two dected on 2nd POD, completely } \\
\text { healed by stenting in ureters for 4 weeks } \\
\text { Another needed reimplantation of ureter in } \\
\text { bladder after 1 month }\end{array}$ & $\begin{array}{l}\text { In long term F/U.- no } \\
\text { residual symptoms }\end{array}$ \\
\hline $\begin{array}{l}\text { Intra-operative } \\
\text { haemorrhage requiring } \\
\text { blood transfussion }\end{array}$ & $4(1.3)$ & Blood transfusion given & $\begin{array}{l}\text { In long term F/U. no residual } \\
\text { symptoms }\end{array}$ \\
\hline
\end{tabular}

Table-VI

Outcome of Laparoscopic hysterectomy, review of the literature.

\begin{tabular}{|c|c|c|c|c|}
\hline Author & $\begin{array}{c}\text { Operative time } \\
\text { (min) }\end{array}$ & $\begin{array}{l}\text { Hospital stay } \\
\text { (days) }\end{array}$ & Complications & $\begin{array}{c}\text { Rate of } \\
\text { conversion }\end{array}$ \\
\hline $\begin{array}{l}\text { Gudia \& Samarria } \\
(2005)^{16}\end{array}$ & $60-180 \min$ & 2.7 & $\begin{array}{l}\text { Overall }-8.5 \% \\
\text { Bladder in }-0.83 \% \\
\text { Ureter in }-0.55 \% \\
\text { Bowel }-0.55 \% \\
\text { One patient - died }\end{array}$ & $1.6 \%$ \\
\hline O' Halan et al $(2017)^{17}$ & $75-185 \min$ & $1.4 \pm .9$ & $\begin{array}{l}\text { Overall }-10 \% \\
\text { Bladder }-1.6 \% \\
\text { Ureter }-1.2 \% \\
\text { Bowel }-0.4 \%\end{array}$ & $0.6 \%$ \\
\hline $\begin{array}{l}\text { Puntambeker et al } \\
(2008)^{13}\end{array}$ & $35-140 \mathrm{~min}$ & $2.21 \pm 1.1$ & $\begin{array}{l}\text { Overall }-5.7 \% \\
\text { Bladder }-1.4 \% \\
\text { Ureter }-0 \% \\
\text { Bowel }-0.7 \%\end{array}$ & No conversion \\
\hline Moon et al $(2011)^{18}$ & $60-145 \min$ & $5.4 \pm 2.9$ & $\begin{array}{l}\text { Overall }-1.4 \% \\
\text { Bladder }-0.48 \% \\
\text { Ureter }-0.19 \% \\
\text { Bowel }-0.19 \%\end{array}$ & $4.2 \%$ \\
\hline Begum et al $(2015)^{19}$ & $110-180 \min$ & $2.89 \pm 1.26$ & $\begin{array}{l}\text { Overall }-2 \% \\
\text { Bladder }-2 \%\end{array}$ & $5 \%$ \\
\hline Bettaiah et al $(2016)^{28}$ & $20-120 \min$ & $2 \pm 0$ & $\begin{array}{l}\text { Overall }-4.8 \% \\
\text { Bladder }-0.23 \% \\
\text { Ureter }-0.47 \% \\
\text { Bowel }-0 \%\end{array}$ & $0.9 \%$ \\
\hline Present study & $50-180$ & $2 \pm 0$ & $\begin{array}{l}\text { Overall }-7 \% \\
\text { Bladder }-1.3 \% \\
\text { Ureter }-1 \% \\
\text { Bowel }-0 \%\end{array}$ & $0.3 \%$ \\
\hline
\end{tabular}




\section{Discussion:}

Total laparoscopic hysterectomy is a substitute for abdominal hysterectomy but not for vaginal hysterectomy. A 2009 Cochrane review stated that vaginal hysterectomy should be performed in preference to abdominal procedures, and that laparoscopic procedure should be considered when the vaginal approach is not possible ${ }^{12}$.

Initially the laparoscopic hysterectomy was started by an expert laparoscopic surgeon who did not use manipulator ${ }^{13}$. After 2 years of our experience, we observed that the introduction of manipulator through vaginal route made the job easier. For new laparoscopic surgeons, we advise to use the manipulator and colpobulger of any form in addition to manipulation by myoma screw. It is not mandatory to use a vaginal manipulator. Nevertheless, Kiel surgeons ${ }^{14}$, Palanivelu ${ }^{8}$ and Mishra ${ }^{15}$ decided to use a manipulator for lot of advantages. Another problem is proper case selection. As an initial procedure larger size uterus should not be handled and with increasing experience gradually increased size of uterus and other complicated cases should be included.

This study observed 298 cases of total laparoscopic hysterectomy. The demographic data including age, parity and body mass index were similar to other studies $^{16,17}$. The most common indication for TLH in our study was leiomyoma (51.7\%) which is similar to the study done by Moon ${ }^{18}$ and Begum ${ }^{19}$.

Most recent studies present TLH as safe, being performed for various indications including malignancy $20-21$. In this study, laparoscopic hysterectomy were started for malignant cases since 2017. Total 12 malignant cases were operated. Endometrial carcinoma were 5 in number. The use of laparoscopic surgery is advocated in international recommendations and guidelines for the treatment of early-stage endometrial cancer 22,23 . Patients operated for border line ovarian malignancy were 5 in number. A Cochrane analysis(2013) came to the conclusion that the existing evidence is insufficient for a scientific evaluation of the benefits and risks of laparoscopy compared to laparotomy to treat earlystage (FIGO stage I) ovarian cancer ${ }^{24}$. In contrast to uterine cancer, the question whether to use laparoscopy in ovarian cancer is still controversially discussed $^{25}$.

About $21.8 \%(n=65)$ had at least one previous abdominopelvic surgery, among them previous caesarean section was the commonest. Initially, patient with history of one caesarean sections were included, gradually history of two and then three caesarean sections cases were included. In this study, no cases were excluded for multiple operations.

Concomitant procedures were performed in $8.4 \%$ cases, without the need for conversion to laparotomy. My co-author was a laparoscopic surgeon, he performed the surgical procedures.

Although the laparoscopic hysterectomy techniques were not identical in all series, our results are nevertheless comparable with those already published regarding operative time, hospital stay, major complications and rate of conversion ( Table 6) ${ }^{13,16-19,28}$.

Different studies observed that TLH is safe and can be performed for a larger size uterus ${ }^{27}$. In this study initially, TLH was done where uterus was less than 20 weeks size but later on bigger sizes were included and maximum sizes operated was 28 weeks size.

The operative time varies between $50 \mathrm{~min}$ to $180 \mathrm{~min}$ for benign cases. In the course of time, the mean operating time dropped from $130 \mathrm{~min}$ to $60 \mathrm{~min}$ for uterine size less than 14 weeks. The operating time seems to be dependent not only on the surgeon's experience but also on factors, such as the number of previous operations, size of the uterus and BMI of the patients.

It is well established that performing TLH involves a learning curve that, with improved skills and technique, will result in a safer procedure with improved outcomes ${ }^{29}$.

Laparoscopy is a safe route provided the surgeons are well trained, because then the rate of complications is not higher than that observed with laparotomy or by vaginal route ${ }^{28}$. In this study the rate of major complication was $3.7 \%$. Complications are slightly higher than some studies ${ }^{20,21}$ because of inclusion of complicated patients.

The mean length of hospital stay was 2 days and return to normal activities within 2 weeks.

Initially, laparoscopic hysterectomy was criticized due to its technical difficulty, increased operative time, and increased number of complications particularly ureteric, bladder, and bowel injuries. But subsequently, studies have shown that laparoscopic hysterectomy has been advantageous compared to 
abdominal hysterectomy which include patient's satisfaction, decreased hospital stay and early return to normal life ${ }^{29}$. Also, laparoscopy allows for easier access to uterine vessels and ureter due to its highdefinition imaging and vision magnification.

Personal experience and daily teaching, however, have shown that the changeover to laparoscopic hysterectomy is not only difficult, but also complicated. This can only be avoided by making the operations more structured and teaching it as early as possible ${ }^{14}$. In public hospitals, patient load is more, operation theatre staffs are not well trained, problems in equipment, lack of cooperation from other supporting staffs and in private hospitals involvement of the cost act as barriers of laparoscopic hysterectomy.

The limitations in our study were that all operations were not done in a single center and estimations of blood loss was not measured in a precise fashion.

\section{Conclusion:}

This study shown that TLH can be performed in most of the benign indications and some malignant cases. It gives the benefit of minimally invasive surgery to the patient like less post-operative infection, less blood loss, and early post-operative recovery with some minimum complications. So, TLH is a safe and acceptable alternative to standard hysterectomy in the hand of expert with improved surgical equipment and in comfortable setting.

\section{References:}

1. Graves EJ. Vital and health statistics, National Hospital Discharge Survey: Annual Summary, 1992, series 13, no 112. National Centre for Health Statistics, Hyattsville, MB, USA.

2. Whiteman MK, Hillis SD, Jamieson DJ. Inpatient hysterectomy surveillance in the United States, 2000-2004. Am J Obstet Gynecol 2008; 198:1-7

3. Turner LC, Shepherd JP, Wang L. Hysterectomy surgery trends: a more accurate depiction of the last decade? Am J Obstet Gynecol 2013; 208: 77: e1-e7

4. Reich H, Decaprio J, Mc Glynn F. Laparoscopic Hysterectomy. J Gynecol. Surge 1989; 5: 213216.

5. Nayeem SA. Manual on Gynecological Laparoscopic Surgery, Japan Bangladesh Friendship Hospital for Endo-Laparoscopic Surgery, 2014, pp. 11, 15.
6. Semm K, CISH (Pelviscopic intrafascial hysterectomy- without colpotomy), TUMA (Total uterine mucosa ablation) and IVH (intrafascial vaginal hysterectomy). Gynacologe 1993; 26: 378-384.

7. Reich H, Mcglynn F, Sekel L. Total laparoscopic hysterectomy. Gynecol Endosc 1993; 2: 59-63.

8. Palanivelu C. Art of Laparoscopic Surgery, Textbook \& Atlas. India: Jaya Publication, 2005, pp-1219-1221, 1223.

9. Garg R, Singh R, Yadav P, Malhotra N. Laparoscopic Hysterectomy: Revisited. J South Asian Feder Obst Gynae 2014; 6(1):1-4.

10. 5. O'Hanlan KA, Dibble SL, Garnier AC. Total laparoscopic hysterectomy: technique and complications of 830 cases. JSL. 2007; 11(1):45-53.

11. Lassen PD, Moeller-Larsen H, De Nully P. Same-day discharge after laparoscopic hysterectomy. Acta Obstet Gynecol Scand. 2012; 91(11):1339-41.

12. Nieboer TE, Johnson N, Lethaby A. Surgical approach to hysterectomy for benign gynaecological disease. Cochrane Database Syst Rev. 2009; 3-4:CD003677.

13. Puntambekar SP, Wagh GN, Puntambekar SS, Sathe RM, Kulkarni MA, Kashyap MA et al. A novel technique of total laparoscopic hysterectomy for routine use: evaluation of 140 cases. International journal of biomedical science 2008 Mar; 4(1):38.

14. Schollmeyer T, Mettler L, Ruther D, Alkatout I. Practical Manual for Laparoscopic \& Hysteroscopic Gynecological Surgery, Kiel School of Gynecological Endoscopy, New Delhi: Jaypee Brothers Medical Publishers, 2013, pp301,304.

15. Mishra RK. Textbook of Practical Laparoscopic Surgery. New Delhi: Jaypee Brothers Medical Publishers, 2013, pp-394.

16. Gudi A \& Samarrai A. A 9-year experience of laparoscopic hysterectomy in a UK district general hospital. Gynecol Surg 2005; 2: 265269

17. O'Hanlan KA, Dibble SL, Garnier AC, Reuland ML. Total laparoscopic hysterectomy: technique 
and complications of 830 cases. Journal of the Society of Laparoendoscopic Surgeons 2007 Jan; 11(1):45.

18. Moon JM, No JH, Jeon YT, Jee BC, Kim YB. Clinical outcomes of 1,041 total laparoscopic hysterectomies: Six years of experience in a single center. Korean Journal of Obstetrics \& Gynecology. 2011 Oct 1; 54(10):618-22.

19. Begum M, Zulfiqar N, Yasmin F. Total Laparoscopic Hysterectomy: A Two-Year Experience in Apollo Hospitals Dhaka. Pulse 2015;8(1):21-9.

20. 14. Karaman $Y$, Bingol B, Gu "nenc, $Z$. Prevention of complications in laparoscopic hysterectomy: experience with 1120 cases performed by a single surgeon. J Minim Invasive Gynecol. 2007; 14:78-84.

21. Bojahr B, Raatz D, Schonleber G. Perioperative complication rate in 1706 patients after a standardized laparoscopic supracervical hysterectomy technique. J Minim Invasive Gynecol 2006; 13:183-9.

22. Galaal K, Bryant A, Fisher AD.Laparoscopy versus laparotomy for the management of early stage endometrial cancer Cochrane Database Syst Rev 20129CD006655

23. Laparoscopic hysterectomy (including laparoscopic total hysterectomy and laparoscopically assisted vaginal hysterectomy) for endometrial cancer. 2010. NICE interventional procedure guidance 3560nline: http://www.nice.org.uk/ipg356last access: 16.09.2014

24. Lawrie $T$ A Mederos L R Rosa D D et al. Laparoscopy versus laparotomy for FIGO stage I ovarian cancer Cochrane Database Syst Rev 20132CD005344

25. Rimbach $\mathrm{S}$, Neis $\mathrm{K}$, Solomayer E, Ulrich U, Wallwiener D. Current and future status of laparoscopy in gynecologic oncology. Geburtshilfe und Frauenheilkunde. 2014 Sep; 74(09):852-9.

26. Scottish intercollegiate Guidelines Network. Management of cervical cancer. 2008; ISBN 978 1905813247

27. 32. Laparoscopic radical hysterectomy for early stage cervical cancer. 20100nline:http:// www.nice.org.uk./guidance/ipg338last access: 16.09.2014

28. Bettaiah R, Reddy CA. Laparoscopic hysterectomies: our 10 years' experience in a single laparoscopic center. The Journal of Obstetrics and Gynecology of India 2016 Aug 1; 66(4):274-281.

29. Wattiez A, Soriano D, Cohen SB. The learning curve of total laparoscopic hysterectomy: comparative analysis of 1647 cases. J Am Assoc Gynecol Laparosc. 2002; 9:339-45. 